\title{
Influence of iron (IV) clathrochelate complex on quail blood parameters and weight characteristics
}

\author{
V.B. Dukhnitsky ${ }^{1}$, I.M. Derkach ${ }^{1 *}$, S.S. Derkach ${ }^{1}$, I.O. Fritsky ${ }^{2}$, M.O. Plutenko ${ }^{2}$ \\ ${ }^{1}$ National University of Life and Environmental Sciences of Ukraine, Kyiv, Ukraine. \\ https://orcid.org/0000-0002-9670-1244, https://orcid.org/0000-0002-0149-7923, https://orcid.org/0000- \\ 0002-6174-1377 \\ *E-mail: Irina1215@ukr.net \\ 2 Taras Shevchenko National University of Kyiv, Kyiv, Ukraine \\ http://orcid.org/0000-0002-1092-8035 \\ https://orcid.org/0000-0002-9369-0711
}

Received: 14.08.2019. Accepted: 26.09.2019

\begin{abstract}
We studied the chronic toxicity of the compounds of Iron(iv). We monitored the dynamics of the body weight, relative weight coefficients of the internal organs, the content of the hemoglobin, the morphological parameters of blood, and biochemical parameters of serum of blood of quails after use of Iron(IV) clathrochelate complexes at the doses $1 / 10$ and $1 / 5$ DL 50 them for 30 days. Daily drinking of quails of experimental groups of solution of Iron(IV) clathrochelate complexes 3 at the doses 76.43 and $152.86 \mathrm{mg} / \mathrm{kg}$ of body weight caused the reduction of body weight by 3 and $5 \%$ respectively on the thirtieth day. A tendency to increase the relative weight of the kidneys and to decrease the relative weight of the liver, heart and spleen showed an excessive load of Iron(IV) clathrochelate complexes on the internal organs of quails. Hemoglobin in the blood of the quails of the experimental groups was less by $2-34 \%(P<0.05)$ than the control indicator but the indicator of the number of erythrocytes in the quails of the control and experimental groups for 30 days was within the physiological values. The use of Iron(IV) clathrochelate complexes caused the development of hypoproteinemia, hypoalbuminemia, and short-term hypoglycemia in the serum of the blood of the quails of the experimental groups. Changes in an activity of alanine aminotransferase and aspartate aminotransferase for 30 days were not expressed, but the activity of alkaline phosphatase was significantly higher compared to the control indicators during the experimental period. Drinking the solution of Iron(IV) clathrochelate complexes caused hypercreatinemia and hyperuricemia, which indicates a decrease in the filtration capacity of the kidney glomeruli. We have seen an increase in the levels total Calcium and inorganic Phosphorus.
\end{abstract}

Key words: Toxicity; Hexahydrazide clathrochelate; Body weight; Morphology; Biochemistry; Quail

\section{Introduction}

An animal health is now regarded as one of the factors of the veterinary well-being in every country, so the issue of treating animals with pathological conditions and their prevention is given considerable attention by both scientists and veterinary practitioners. In conditions of intensive animal husbandry, the load on evolutionarily produced adaptive reactions of the organism of animals under the action of ecological and technological factors significantly increases. This is accompanied by an increase in its reactivity, the stress of metabolic processes, changes in functions at the cellular, organ and system levels. Modern breeds of farm animals and poultry, selected for their high growth rate and egg production, are more sensitive to a variety of stressors. They require the introduction of high levels of vitamins and trace elements into the diet to realize their genetic potential (Dozier et al. (2003); Miles et al. (2003); Gheisari et al. (2011); Shahzad et al. (2012); Vasanth et al. (2015); Holubiev \& Holubieva (2017); Holubiev et al. (2017); Pozniakovskyi et al (2018). The main directions of modern approaches to the study of the normalization of the physiological potential of animals / birds are a development of optimal conditions of confinement with limitation of adverse environmental factors, breeding work for the creation of rocks with high immunological status and pharmacological correction with the use of drugs of relevant pharmacological groups. The formation of the latter direction is associated with the creation of new groups of drugs that can guarantee the implementation of preventive measures. In view of the above, one of the main directions of work of scientists of veterinary medicine in general and one of the tasks of modern practical toxicology is to determine the parameters of toxicodynamics and toxicokinetics of new substances to identify risk factors and prevent their negative impact on the body of agricultural and wild animals and humans. Today in addition to the need to feed vitamins and trace elements antianemic drugs are one of the most common pharmacological groups used for the prevention and treatment of non-contagious animal diseases. It is not possible to solve the problem of animal/poultry iron deficiency states without the creation of drugs with Iron as an active substance. Analysis of the state of provision of the pharmaceutical market with such veterinary drugs shows that manufacturers use irondextran complexes which includes Iron in valences II and III (Derkach, 2017). Now there is enough scientific research about the use of this trace element, but only issues related to low valent Iron compounds have been studied in sufficient detail. They focus on the rare unconventional degree of oxidation +4 , which is realized in the catalytic cycles of many Iron containing enzymes (Gloves et al., 
2006; England et al., 2014; Tang et al., 2015; Tomyn et al., 2017). But the biological activity of substances of this type has not been studied, in particular its effect on the pig organism, pharmacokinetics and pharmacodynamics has not been clarified. Preclinical studies are required before a conducting such experiments (Kotsiumbas, 2006). We have previously reported on the study of the effect of Iron(IV) clathrochelate complexes on the basis of macrobicyclic ligand hexahydrazide type on the body of white mice (Dukhnitsky et al., 2018) and its cumulative properties in white rats (Dukhnitsky et al., 2018). Questions regarding preclinical studies remain open, in particular the toxicological aspects, namely the study of chronic toxicity, need to be refined. According to the world literature, this issue is poorly understood and is being developed for the first time in Ukraine, so it is important for scientific and practical veterinary medicine.

Thus, there is a problem of finding new effective anti-anemic agents that will be able to provide the physiological need of animals of all species and age groups in Iron, and which are largely devoid of side effects. Before studying the pharmacodynamics and pharmacokinetics in the organism of farm animals (primarily pigs), it is necessary to scientifically justify the doses of such drugs. For this purpose it is necessary to make all preclinical research. Therefore, a detailed study of pharmacodynamics and pharmacokinetics of Iron will allow to regulate the doses of its preparations for growing animals, primarily pigs, which will help to prevent the development of iron deficiency conditions and anemia, negative impact on the young body. The purpose of the study is to reseach the effect of solutions of Iron(IV) clathrochelate complexes at the different concentrations on the organism of the quails with the determination of the dynamics of body weight, relative coefficients of mass of their internal organs, morphological and biochemical parameters of blood and blood serum with repeated administration of various substances in the study.

\section{Methods}

The experiment on the research chronic toxicity of Iron(IV) clathrochelate complexes $\mathrm{Na}_{2}[\mathrm{Fe}(\mathrm{L}-6 \mathrm{H})] \cdot 2 \mathrm{H}_{2} \mathrm{O}(\mathrm{L}-$ macrobicyclic hexahydrazide ligand) were performed on the quails with body weight 160-170 g. The poultry was divided into three groups with 15 quails in each. The quails of group I (control) drinked water; the quails of group II were drinked the solution of Iron(IV) clathrochelate complexes from the calculation $76.43 \mathrm{mg} / \mathrm{kg}$ body weight (1/10 DL 50 of test compound); the quails of group III were drinked the solution of Iron(IV) clathrochelate complexes from the calculation $152.86 \mathrm{mg} / \mathrm{kg}$ body weight (1/5 DL 50 of test compound). The choice of quails for the experiment is due to the fact that today they are considered one of the most profitable and demonstration models for conducting experiments. It is also known that the development and use of modern sources of trace elements in the form of chelate compounds with essential amino acids in combination with antioxidants and $\beta$-carotene are now being developed and used in the feeding of quails are relevant and include studies of the effect of these components on the morphological parameters and chemical composition of industrial quail eggs and further study of their effect on progeny (Spears et al., 2004). Therefore, in the next phase of our research, we used quails to study the chronic toxicity of Iron in unconventionally rare valence - IV. The pourtly was kept in the conditions of the vivarium of the Faculty of Veterinary Medicine of the National University of Life and Environmental Sciences of Ukraine with constant temperature and humidity of the air in the rooms. The feeding of quails provided a standard diet with constant access to water/solution of Iron(IV) clathrochelate complexes. Before the experiment, the poultry of all groups was kept in the adaptation period for 10 days. There were no deviations in the behavioral responses of the quails in the experimental and control groups. During the whole experiment, the birds were monitored and taken into account the general condition, nature and degree of activity, coordination of movement, the presence of tremors, seizures, paresis, paralysis, eye, nose, discoloration of feathers and appetite. The quails also weighed and noted changes in their body weight. To determine the relative coefficients of mass of internal organs, conducting morphological and biochemical studies on the 10th, 20th and 30th days of the experiment, under the conditions of light ether anesthesia, euthanasia of 5 quails from each group was performed. Sampling of biological material was performed according to the European Convention for the Protection of Vertebrate Animals used for Experimental and Other Scientific Purposes (Strasbourg, 1986) and General Ethical Principles of Experiments on Animals, adopted by the First National Bioethics Congress (Kyiv, 2001). The experiments were conducted in accordance with the principles of humanity set out in the Directive of the European Community. Determination of morphological and biochemical parameters of blood and serum was performed by conventional methods. The results obtained were processed by the method of variational statistics using an Excel computer program, the results of the mean values were considered statistically significant at $P \leq 0.05$.

\section{Results and discussion}

Experimental studies have found that the drinking of quails a solution of Iron(IV) clathrochelate complexes in the form of clathrochelate at the doses 76.43 and $152.86 \mathrm{mg} / \mathrm{kg}$ body weight did not cause visible signs of intoxication and death of the poultry. On 10th and 20th days of observation all quails had an appetite, the behavioral responses were adequate and showed the reflecting the normal functional state of the central nervous system. On the 30th day the correlation pattern of values of the used doses of the drug with the suppressed state of quails in the experimental groups was noted. The feather cover lost its luster, it was squatting, the aftertaste was of a soft consistency, and the body weight decreased compared to the indicators in the control poultry (Table 1).

Table 1. Change in the body weight ( $\mathrm{g}$ ) of quails during prolonged use of the solution of the Iron(IV) clathrochelate complexes (M $\pm m, n=5)$.

\begin{tabular}{|c|c|c|c|c|}
\hline \multirow{2}{*}{ Group } & \multicolumn{4}{|c|}{ Day of research } \\
\hline & 1st & 10 th & 20th & 30th \\
\hline I Control & $167.4 \pm 2.62$ & $241.0 \pm 3.82$ & $321.8 \pm 3.2$ & $387.8 \pm 1.69$ \\
\hline II Experimental & $164.4 \pm 1.91$ & $242.2 \pm 2.29$ & $322.7 \pm 2.91$ & $375.4 \pm 2.41 * *$ \\
\hline III Experimental & $165.8 \pm 1.70$ & $243.0 \pm 1.78$ & $324.7 \pm 0.84$ & $370.4 \pm 3.65^{* *}$ \\
\hline
\end{tabular}

$* \mathrm{P}<0.05, * * \mathrm{P}<0.01, * * * \mathrm{P}<0.001$ in the comparison to the control group.

It was found that the body weight of the quails of the experimental groups was slightly greater at 10 days, not different from the indicator in the quails of the control group at 20 days, whereas at 30 days was significantly reduced by $3 \%$ (Iron(IV) clathrochelate complexes at a dose $76.43 \mathrm{mg} / \mathrm{kg}$ body weight) and 5\% (Iron(IV) clathrochelate complexes at a dose $152.86 \mathrm{mg} / \mathrm{kg}$ body weight) in quails of experimental groups respectively compared to control. 
In addition to changes in body weight, important changes that reflect the level of metabolic processes in the body of poultry through its intoxication are changes in the mass of individual organs (Table 2).

Table 2. Change in relative mass of the organs (\%) of quails after prolonged use of the solution of the Iron(IV) clathrochelate complexes $(M \pm m, n=5)$.

\begin{tabular}{lcccc}
\hline Organ & Group & 10th & $\begin{array}{c}\text { Day of research } \\
\text { 20th }\end{array}$ & 30th \\
\hline \multirow{3}{*}{ Liver } & & $7.8 \pm 0.22$ & $8.1 \pm 0.39$ & $8.4 \pm 0.35$ \\
& I & $4.9 \pm 0.36^{* * *}$ & $3.1 \pm 0.32^{* * *}$ & $3.0 \pm 0.37^{* * *}$ \\
Heart & II & $4.1 \pm 0.12^{* * *}$ & $2.9 \pm 0.14^{* * *}$ & $2.6 \pm 0.24 * * *$ \\
& III & $0.2 \pm 0.02$ & $0.2 \pm 0.01$ & $0.2 \pm 0.01$ \\
Kidneys & I & $0.1 \pm 0.02$ & $0.2 \pm 0.01$ & $0.2 \pm 0.02$ \\
& II & $0.1 \pm 0.02$ & $0.2 \pm 0.02$ & $0.1 \pm 0.02$ \\
& III & $6.0 \pm 0.26$ & $6.4 \pm 0.22$ & $7.4 \pm 0.15$ \\
Spleen & I & $6.4 \pm 0.42$ & $6.6 \pm 0.33$ & $0.14^{*}$ \\
& II & $6.6 \pm 0.45$ & $6.8 \pm 0.15$ & $0.6 \pm 0.15^{* *}$ \\
\hline
\end{tabular}

Note: See Table 1.

The analysis of the coefficients of the mass of the internal organs of the quails for 10 days showed a significant increase in the weight of the kidneys and a decrease in the weight of the liver, heart and spleen in the poultry of the experimental groups; at doses of $152.86 \mathrm{mg} / \mathrm{kg}$ body weight (III experimental group) these changes are more pronounced, than at the doses of $76.43 \mathrm{mg} / \mathrm{kg}$ body weight compared to the values in the quails of a control group. On the 20th day, the same tendency of changes of relative coefficients of mass of internal organs of quails is established.

Changes in the relative coefficients of the mass of the internal organs of the quails of the experimental groups for 30 days were characterized by an increase in the mass of the kidneys by $9 \%(P<0.05)$ (II experimental group) and by $12 \%$ (III experimental group) and a marked decrease in liver weight by 2.8 times $(\mathrm{P}<0,001)$ (II experimental group) and by 3.2 times ( $\mathrm{P}<0.001)$ (III experimental group) compared with the indicators in the control poultry. The relative weight ratios of the heart and spleen were smaller, respectively by 14 and $50 \%$ in the quails of III experimental group (at a dose $152.86 \mathrm{mg} / \mathrm{kg}$ body weight) compared to the indicators of the poultry in the control group. This indicates an excessive burden on these quail organs with Iron(IV) clathrochelate complexes. The most informative for pre-clinical studies is the blood system, which reflects changes in homeostasis of the body due to the toxic effects of the test substances (Table 3).

Table 3. Change in the content of hemoglobin and the morphological parameters of the blood of the quails during prolonged use of the solution of the Iron(IV) clathrochelate complexes ( $\pm m, n=5)$.

\begin{tabular}{lcccc}
\hline \multicolumn{1}{c}{ Indicator } & $\begin{array}{c}\text { Group } \\
\text { of quails }\end{array}$ & 10th & $\begin{array}{c}\text { Day of research } \\
\text { 20th }\end{array}$ & 30th \\
\hline Hemoglobin, & I & $121.7 \pm 3.48$ & $130.3 \pm 2.19$ & $123.3 \pm 3.66$ \\
g/L & II & $99.0 \pm 3.60^{* *}$ & $112.9 \pm 5.64 *$ & $121.0 \pm 3.63$ \\
& III & $80.2 \pm 4.21^{* * *}$ & $93.5 \pm 3.68^{* * *}$ & $107.8 \pm 1.25^{*}$ \\
Erythrocytes, & I & $3.0 \pm 0.16$ & $3.6 \pm 0.08$ & $4.0 \pm 0.04$ \\
$10^{12} / \mathrm{L}$ & II & $2.4 \pm 0.14 *$ & $3.0 \pm 0.05^{* * *}$ & $3.9 \pm 0.06$ \\
& III & $3.2 \pm 0.17$ & $3.1 \pm 0.04 * * *$ & $3.6 \pm 0.09 *$ \\
Hematocrit, $\%$ & I & $47.8 \pm 1.11$ & $51.2 \pm 0.89$ & $49.3 \pm 0.49$ \\
& II & $45.6 \pm 0.54$ & $44.8 \pm 0.44 * * *$ & $47.2 \pm 0.51^{*}$ \\
Leukocytes, & III & $43.1 \pm 1.88$ & $42.4 \pm 0.44 * * *$ & $46.1 \pm 0.73 * *$ \\
$10^{9} / \mathrm{L}$ & I & $57.3 \pm 0.41$ & $66.1 \pm 1.08$ & $61.2 \pm 0.23$ \\
& II & $54.1 \pm 2.22$ & $60.5 \pm 2.29$ & $61.6 \pm 0.31$ \\
Platelets, $10^{9} / \mathrm{L}$ & III & $46.2 \pm 2.79 *$ & $56.4 \pm 1.38^{* *}$ & $62.8 \pm 1.05$ \\
& I & $34.3 \pm 2.19$ & $44.4 \pm 1.45$ & $47.7 \pm 0.66$ \\
\hline
\end{tabular}

Note: See Table 1.

The hemoglobin content in the blood of quails of the II and III experimental groups was significantly lower than that of the pourtly of control group on 10th day by $19(P<0.01)$ and $34 \%(P<0.001)$ respectively; on 20th day - by $13(P<0.05)$ and $28 \%(P<0.001)$; on 30th day - by 2 and $13 \%(P<0.05)$ respectively. The number of erythrocytes in the quails of the control and experimental groups within 30 days was within physiological values.

Due to the effect of solution of the Iron(IV) clathrochelate complexes hematocrit in the blood of poultry of II and III experimental groups during the whole study period was significantly lower than in the control: on 10th day by 5 and $10 \%$ respectively; on 20 th day - by 13 and $17 \%(P<0.001)$; on 30th day - by $4(P<0.05)$ and $6 \%(P<0.01)$ respectively.

The number of leukocytes in the blood of the quails of experimental II and III groups at 10 and 20 days of observation was lower compared to the parameters in the control poultry. On day 30th an increase in the leukocyte count in the blood of the quails of the experimental groups was observed to the level of the indicator in the control poultry. 
The number of platelets in the blood of the quails of both control and experimental groups increased over 30 days of observation, but in the experimental groups the poultry was less than the control. Thus, for 30 days, the number of platelets in the blood of the quails of the second experimental group was $84 \%(\mathrm{P}<0.001)$ and in the blood of the quails of the 3th experimental group was $77 \%$ $(P<0.001)$ from the indicator of quails of the control group.

Among the biochemical parameters of the serum of the quail, the largest changes were observed in the indicators of non-protein nitrogen compounds, alkaline phosphatase activity and glucose and macroelement content (Table 4).

As can be seen from the data in Table 4 the content of the total protein and albumin in the serum of the blood of the quails in the experimental groups for 30 days were at the same level as in the control group.

The use of Iron(IV) clathrochelate complexes resulted in a steady decrease the level of glucose in the serum of the blood of quails in II and III experimental groups for 20 days. Thus, on 10th days its level was lower than the control indicator by 12 (II experimental group) and 22\% ( $<<0.01$ ) (III experimental group) and on 20th day by 6 (II experimental group) and $16 \%$ (P<0.001) (III experimental group).

Enzymes play a crucial role in ensuring normal metabolism, which is crucial for maintaining homeostasis. According to the results of our studies, the activity of ALT and AST in the serum of the blood of the quails of the experimental II and III groups within 30 days did not differ significantly from the serum levels of the quails of the control group.

The activity of alkaline phosphatase in the serum of the quails of the experimental groups was significantly higher than in the control during the whole experimental period and on 30th day it was higher by 1.5 times $(P<0.001)$ than in the control group.

In our experiment the changes of creatinine and uric acid underwent significant changes under the influence of Iron(IV) clathrochelate complexes. Thus, on the 10th day after application of the experimental drug the content of creatinine in the serum of the blood of the quails in the second experimental group was higher than the indicator in the poultry of the control group by almost $7 \%$, and in the serum of the blood of the quails in the third experimental group by $27 \%(\mathrm{P}<0.001)$. During the subsequent study periods, the content of creatinine in the serum of the blood of the quails of the II experimental group was no different from the control. And in the quails of the third experimental group (dose of Iron(IV) clathrochelate complexes $152.86 \mathrm{mg} / \mathrm{kg}$ body weight) was significantly higher than the control index after 20 days by $11 \%(P<0.01)$, after 30 days - by $7 \%(P<0.05)$.

The lever of uric acid in the serum of the blood of the quails both experimental groups on the 10th was slightly lower than in the control group, but after 20 days it grew and exceeded the control indicator by $30 \%(P<0.001)$ in the quails of II experimental group and by $35 \%(P<0.001)$ in the quails of III experimental group. On 30th day the content of uric acid in the serum of the blood of the poultry in II experimental group was bigger than in the control by $21 \%(P<0.001)$, in the poultry in III experimental group - by $28 \%(P<0.001)$.

Table 4. Change in the biochemical parameters of the serum of the blood of the quails during prolonged use of the solution of the Iron(IV) clathrochelate complexes $(M \pm m, n=5)$.

\begin{tabular}{|c|c|c|c|c|}
\hline \multirow{2}{*}{ Parameters } & \multirow{2}{*}{ Group } & \multicolumn{3}{|c|}{ Day of research } \\
\hline & & 10th & 20th & 30th \\
\hline Total & $\mathrm{I}$ & $26.6 \pm 0.70$ & $25.8 \pm 0.19$ & $26.3 \pm 0.34$ \\
\hline \multirow[t]{2}{*}{ protein, $\mathrm{g} / \mathrm{L}$} & II & $25.6 \pm 0.46$ & $25.9 \pm 0.63$ & $27.0 \pm 0.28$ \\
\hline & III & $25.0 \pm 0.79$ & $25.1 \pm 0.38$ & $25.2 \pm 0.18^{*}$ \\
\hline \multirow[t]{3}{*}{ Albumins, \% } & $\mathrm{I}$ & $14.8 \pm 0.71$ & $14.2 \pm 0.53$ & $15.1 \pm 0.78$ \\
\hline & II & $15.3 \pm 1.46$ & $15.6 \pm 0.96$ & $15.4 \pm 1.12$ \\
\hline & III & $14.1 \pm 1.86$ & $15.2 \pm 1.04$ & $14.9 \pm 0.14$ \\
\hline \multirow[t]{3}{*}{ Glucose, mmol/L } & $\mathrm{I}$ & $15.2 \pm 0.70$ & $19.7 \pm 0.46$ & $17.3 \pm 0.33$ \\
\hline & II & $13.4 \pm 0.74$ & $18.5 \pm 0.56$ & $16.8 \pm 0.17$ \\
\hline & III & $11.9 \pm 0.36 * *$ & $16.5 \pm 0.32 * * *$ & $17.8 \pm 0.19$ \\
\hline \multirow[t]{3}{*}{$\mathrm{ALT}, \mathrm{mmol}(\mathrm{h} \cdot \mathrm{L})$} & $\mathrm{I}$ & $0.3 \pm 0.01$ & $0.2 \pm 0.01$ & $0.2 \pm 0.01$ \\
\hline & II & $0.2 \pm 0.01$ & $0.3 \pm 0.02 *$ & $0.3 \pm 0.01^{* * *}$ \\
\hline & III & $0.3 \pm 0.2$ & $0.3 \pm 0.02$ & $0.3 \pm 0.01 * *$ \\
\hline \multirow[t]{3}{*}{ AST, mmol/(h.L) } & $\mathrm{I}$ & $2.5 \pm 0.13$ & $3.3 \pm 0.19$ & $3.4 \pm 0.18$ \\
\hline & II & $2.3 \pm 0.17$ & $3.0 \pm 0.20$ & $3.3 \pm 0.14$ \\
\hline & III & $2.1 \pm 0.11^{*}$ & $2.7 \pm 0.17^{*}$ & $3.0 \pm 0.17$ \\
\hline Alkaline & $\mathrm{I}$ & $341.3 \pm 14.4$ & $338.4 \pm 5.28$ & $319.7 \pm 17.08$ \\
\hline \multirow{2}{*}{$\begin{array}{l}\text { phosphatase, } \\
\mathrm{mmol} /(\mathrm{h} \cdot \mathrm{L})\end{array}$} & II & $391.2 \pm 16.5^{*}$ & $436.8 \pm 18.4^{* *}$ & $463.7 \pm 17.2^{* * *}$ \\
\hline & III & $414.5 \pm 12.8^{* *}$ & $441.3 \pm 10.17 * * *$ & $467.1 \pm 18.7^{* * *}$ \\
\hline \multirow{3}{*}{$\begin{array}{l}\text { Creatinine, } \\
\mathrm{mkmol} / \mathrm{L}\end{array}$} & $\mathrm{I}$ & $61.8 \pm 1.73$ & $64.7 \pm 1.10$ & $59.9 \pm 0.82$ \\
\hline & II & $66.4 \pm 3.06$ & $64.9 \pm 1.05$ & $60.5 \pm 0.70$ \\
\hline & III & $78.2 \pm 1.43^{* * *}$ & $71.6 \pm 1.26 * *$ & $64.3 \pm 1.24 *$ \\
\hline \multirow{3}{*}{$\begin{array}{l}\text { Uric acid, } \\
\text { mkmol/L }\end{array}$} & I & $253.2 \pm 5.39$ & $269.1 \pm 4.02$ & $277.9 \pm 3.85$ \\
\hline & II & $239.9 \pm 6.81$ & $349.2 \pm 3.04 * * *$ & $336.0 \pm 6.92^{* * *}$ \\
\hline & III & $219.0 \pm 3.97 * * *$ & $362.2 \pm 3.84 * * *$ & $354.6 \pm 7.68^{* * *}$ \\
\hline \multirow{3}{*}{$\begin{array}{l}\text { Total Calcium, } \\
\mathrm{mmol} / \mathrm{L}\end{array}$} & $\mathrm{I}$ & $1.6 \pm 0.09$ & $1.8 \pm 0.05$ & $2.1 \pm 0.07$ \\
\hline & II & $2.3 \pm 0.24^{*}$ & $3.2 \pm 0.17^{* * *}$ & $2.6 \pm 0.18^{*}$ \\
\hline & III & $2.5 \pm 0.09 * * *$ & $3.4 \pm 0.21 * * *$ & $2.7 \pm 0.28$ \\
\hline Inorganic & $\mathrm{I}$ & $1.3 \pm 0.06$ & $1.0 \pm 0.05$ & $1.2 \pm 0.02$ \\
\hline Phosphorus, & II & $2.2 \pm 0.12^{* * *}$ & $2.7 \pm 0.39 * *$ & $1.2 \pm 0.11$ \\
\hline $\mathrm{mmol} / \mathrm{L}$ & III & $2.4 \pm 0.22 * *$ & $2.8 \pm 0.15^{* * *}$ & $1.4 \pm 0.18$ \\
\hline
\end{tabular}

Note: See Table 1.

We believe that the main reasons for the increase in the content of non-protein compounds of nitrogen (creatinine, uric acid) in the serum of the blood of the quails of the experimental groups are impaired absorption of amino acids in the intestine increased their decomposition and impaired purine metabolism. It is quite possible that impaired renal function is caused by a prolonged intake of Iron(IV) clathrochelate complexes, a decrease in the filtration capacity of the renal glomeruli which leads to a delay in the excretion 
of uric acid and creatinine. In our experiments we found that the content total Calcium and inorganic Phosphorus in the serum of the blood of the quails intoxicated with Iron(IV) clathrochelate complexes were changing.

Thus, the content of total Calcium, which together with the glucose indicator reflects the functional state of the pancreas in the body, testified to persistent hypercalcemia. Its degree of manifestation was dependent on the dose of the test substance. Thus, the content of total Calcium in the serum of the blood of the quails of II experimental groups (dose of Iron(IV) clathrochelate complexes $76.43 \mathrm{mg} / \mathrm{kg}$ body weight) on the 10 th day was higher by 1.4 times $(\mathrm{P}<0.05)$; on the 20 th day - by 1.7 times $(P<0.001)$; on the 30th day - by 1.2 times $(P<0.05)$ compared to the control. The content of total Calcium in the serum of the blood of the quails of III experimental groups (dose of Iron(IV) clathrochelate complexes $152.86 \mathrm{mg} / \mathrm{kg}$ body weight) was higher by $1.6(P<0.001), 1.9(P<0.001)$ and 1.3 times respectively. A similar trend in changes in indicators was observed for Phosphorus inorganic: in the serum of the quails of the second experimental group, its content on the 10th day was higher by 1.7 times $(P<0.001)$; in the serum of quails of the third experimental group it was higher by $1.8(P<0.01)$ times that the control indicator. For 20 days in the serum of poultry of both experimental groups the content of Phosphorus inorganic significantly increased almost by 3 times relative to the control indicator and for 30 days it decreased to physiological values.

\section{Conclusion}

According to our goal, the comprehensive research of the influence of Iron(IV) clathrochelate complexes at the doses $1 / 10$ DL 50 (76.43 $\mathrm{mg} / \mathrm{kg}$ body weight) and $1 / 5 \mathrm{DL}_{50}(152.86 \mathrm{mg} / \mathrm{kg}$ body weight) during prolonged application to the body of quails was performed for the first time. This made it possible to establish the basic patterns of metabolic disorders and physiological functions under the action of the test substance. Daily drinking of the solution of Iron(IV) clathrochelate complexes caused the decrease of body weight of the quails in experimental groups by 3 and $5 \%$ respectively (on the 30th day).

The tendency to increase of relative mass of kidney by $9 \%(P<0.05)$ (II experimental group) and by $12 \%$ (III experimental group) and to marked decrease of relative mass of liver by 2.8 times $(P<0.001$ ) (II experimental group) and 3.2 times ( $P<0.001$ ) (III experimental group) compared with the control group on the 30th day shows the excessive load on the internal organs of quails under the influence of Iron(IV) clathrochelate complexes. The relative ratios of the weight of heart and spleen were lower by 14 and $50 \%$ respectively in the quails of the third experimental group (at a dose of $152.86 \mathrm{mg} / \mathrm{kg}$ body weight) compared with those in the control poultry.

The content of hemoglobin in the blood of the quails of the experimental groups was less than the control indicator by $2-34 \%$ $(P<0.05)$. Due to the influence of the solution of Iron(IV) clathrochelate complexes the hematocrit in the blood of poultry II and III of the experimental groups during the whole experimental period was significantly lower on the 30 th day by $4(P<0.05)$ and $6 \%$ $(P<0.01)$ respectively. The number of erythrocytes in the quails of the control and experimental groups within 30 days was within the physiological values. On 30th day the number of platelets in the blood of the quails of the second experimental group were $84 \%$ $(P<0.001)$, in the blood of the quails of the third experimental group $-77 \%(p<0.001)$ from the indicator in the control group bird. The results of biochemical examination of the serum of the blood demonstrate the development of hypoproteinemia and hypoalbuminemia, the decrease of the level of glucose in the serum of the blood of quails in II and III experimental groups for only 20 days; on the 30th day his indicator did not differ from the control. Among the enzymes, only activity of alkaline phosphatase was significantly altered: in the serum of the blood of the quails in the experimental groups it was significantly higher than in the control during the whole experimental period and on the 30th day it was higher by 1.5 times $(P<0.001)$ than the indicator of the poultry in the control group. The drinking a solution of Iron(IV) clathrochelate complexes in appropriate doses led to a significant increase the levels of creatinine (hypercreatinemia) and uric acid (hyperuricemia) in serum of the blood of quails in experimental groups that it is indicating a decrease in the filtration capacity of the glomeruli of kidney. We also observed an increase in the content of Total Calcium and Inorganic Phosphorus.

\section{References}

Dozier, W.A., Davis, A.J., Freeman, M.E., \& Ward, T.L. (2003). Early growth and environmental implications of dietary zinc and copper concentrations and sources of broiler chicks. Br. Poult. Sci., 44, 726-731. https://doi.org/10.1080/00071660310001643714 Dukhnitsky, V. B., Derkach, I. M., Plutenko, M. O., Fritsky, I. O., \& Derkach, S. S. (2018). Vyznachennja parametriv gostroi toksychnosti ferumu (IV) na bilyh myshah. Ukrainian Journal of Ecology, 8 (2), 308-312. https://doi.org/10.15421/2018 343 (in Ukrainian).

Dukhnitsky, V. B., Derkach, I. M., Plutenko, M. O., Fritsky, I. O., \& Derkach, S. S. (2019). Cumulative properties of Iron(IV) clathrochelate in rats. Visnyk PDAA, 2, 2382-46.

Derkach, I. (2017). Suchasni tendencii na vitchyznjanomu rynku ferumvmisnyh preparativ dlja tvaryn. Naukovyj visnyk Lvivskogo nacionalnogo universytetu veterynarnoi medycyny ta biotehnologij imeni S.Z. Gzhyckogo, 19 (78), $23-25$. https://doi.org/10.15421/nvlvet7805 (in Ukrainian).

Commission of the European Communities: Council Directive of 18 December 1986 on the Lows, regulating the Application of Principles of Good Laboratory Practice and the Verification of Their Applications for Tests on Chemical Substances (87/18/EEC) (1991). The Rules Governing Medicinal Products in the European Community. 1, 145-146.

Jiefen, C., Yinping, L., Peng, Y., Qiping, Zh., Jingfeng, W., Yongzhou, Ch., \& Peng, W. (2017). A novel low molecular weight Enteromorpha polysaccharide-iron (III) complex and its effect on rats with iron deficiency anemia (IDA). International journal of biological macromolecules. 108, 412-418. https://doi.org/10.1016/j.ijbiomac

England, J. Bigelow, O., Katherine, M., Heuvelen, V., Farquhar, E., Martinho, M., Meier, K., Frisch, J., Münck E., \& Que L. (2014). An ultra-stable oxoiron (IV) complex and its blue conjugate base. Chemical Science, 5, 12041-215. doi:10.1039/C3SC52755G

Gheisari, A.A., Sanei, A. Samie, A., Gheisari, M.M., \& Toghyani. M. (2011). Effect of diets supplemented with different levels of manganese, zinc, and copper from their organic or inorganic sources on egg production and quality characteristics in laying hens. Biol Trace Elem Res, 142(2011), 557-571. https://doi.org/10.1007/s12011-010-8779-x

Groves, J. T. (2006). High-valent iron in chemical and biological oxidations. Journal of Inorganic Biochemistry, 100(4), 4344-47. https://doi.org/10.1016/j.jinorgbio.2006.01.012

Holubiev, M., \& Holubieva, T. (2017). The productivity of young quail at the usage of different sources of zinc in fodders.Scientific Messenger of LNU of Veterinary Medicine and Biotechnologies. Series: Agricultural Sciences, 19(74), 127-130. https://doi.org/10.15421/nvlvet7428 
Holubiev, M.I., M.Yu. Sychov, M.Yu., \& Holubieva, T.A. (2017). Effect of copper as feed additives on growth performance in quail chicks. Ukrainian Journal of Ecology, 7(2), 59-63. DOI: http://dx.doi.org/10.15421/2017 21

Kim, J.C., Wilcock, P., \& Bedford, M.R. (2018). Iron status of piglets and impact of phytase superdosing on iron physiology: A review. Animal Feed Science and Technology, 235, 81-84.

Kotsiumbas I.Ya. (2006) Doklinichni doslidzhennja veterynarnyh likars'kyh zasobiv. L'viv. Triada pljus (in Ukrainian).

Lipiński, P., Starzyński, R., Canonne-Hergaux, F., Tudek, B., Oliński, R., Kowalczyk, P., Dziaman, T., Thibaudeau, O., Gralak, M. A., Smuda, E., Woliński, J., Usińska, A., \& Zabielski R. (2010). Benefits and Risks of Iron Supplementation in Anemic Neonatal Pigs. American journal of hematology, 177(3), 123-31243. doi: https://10.2353/ajpath.2010.091020.

Maes, D., Steyaert, M., Vanderhaeghe, C., López Rodríguez, A., de Jong, E., Del Pozo Sacristán, R., Vangroenweghe, F., \& Dewulf, J. (2011) Comparison of oral versus parenteral iron supplementation on the health and productivity of piglets. Veterinary record, 19 , 168-188. doi: https://10.1136/vr.c7033

Miles, R., Henry, P., Sampath, V., Shivazad, M., \&Comer, C. (2003). Relative bioavailability of novel amino acid chelates of manganese and copper for chicks. J. Appl. Poult. Res., 12 (2003), pp. 417-423. https://doi.org/10.1093/japr/12.4.417

Pozniakovskyi, Yu.V., Holubiev, M.I., \& Holubieva, T.A. (2018). Productivity of growing rabbits for use of forrage with different zinc content. Ukrainian Journal of Veterinary and Agricultural Sciences, 1(2), 3-6.

Shahzad, M.N., Javed, M.T., Shabir, S., Irfan, M., \& Hussain, R. (2012). Effects of feeding urea and copper sulphate in different combinations on live body weight, carcass weight, percent weight to body weight of different organs and histopathological tissue changes in broilers. Exp. Toxicol. Path., 64, 141-147. https://doi.org/10.1016/j.etp.2010.07.009

Spears, J.W., Schlegel, P., Seal, M.C., \& Lloyd, K.E. (2004). Bioavailability of zinc from zinc sulfate and different organs zinc sources and their effects on ruminal volatile fatty acid proportions. Livestock Production Science, 90, 2-3, 211-217.

Streyl, K., Carlstron, J., Dantos, E., Mendoza, R., Islas, J.A., \& Bhushan C. (2015). Field Evaluation of the Effectiveness of an Oral Toltrazuril and Iron Combination (Baycox® Iron) in Maintaining Weaning Weight by Preventing Coccidiosis and Anaemia in Neonatal Piglets, 114 (1), 1932-00. doi: https://10.1007/s00436-015-45254-529

Todoriuk, V. B., Hunchak, V. M., Gutyj, B. V., Gufriy, D. F., Hariv, I. I., Khomyk, R. I., \& Vasivhttps, R. O. (2018). Preclinical research of the experimental preparation "Ferosel T". Ukrainian Journal of Veterinary and Agricultural Sciences, 1, 3-9. https://doi.org/10.15421/ujvas0101

Tomyn, S., Shylin, S. I., Bykov, D., Ksenofontov, V., Gumienna-Kontecka, E., Bon, V., \& Fritsky, I.O. (2017) Indefinitely stable iron (IV) cage complexes formed in water by air oxidation. Nature Communications, 8, 1-8.

Vasanth, S., Dipu, M.T., Mercy, A.D., \& Shyama, K. (2015). Studies on production performance in broiler chicken supplementing copper and flavomycin in feed. International Journal of Technical Research and Applications, 3(3), $269-272$.

\section{Citation:}

V.B. Dukhnitsky, I.M. Derkach, S.S. Derkach, I.O. Fritsky, M.O. Plutenko (2019). Influence of iron (IV) clathrochelate complex on quail blood parameters and weight characteristics. Ukrainian Journal of Ecology, 9(3), 126-131.

(cc) EY This work is licensed under a Creative Commons Attribution 4.0. License 